\title{
Immigration and Violent Crime: Evidence from the Colombia-Venezuela Border*
}

\author{
Bravo Working Paper \# 2020-021
}

\author{
Brian Knight $^{\dagger} \quad$ Ana Tribin $^{\ddagger}$
}

\begin{abstract}
This paper investigates the link between violent crime and immigration using data from Colombian municipalities during the recent episode of immigration from Venezuela. The key finding is that, following the closing and then re-opening of the border in 2016, which precipitated a massive immigration wave, homicides in Colombia increased in areas close to the border with Venezuela. Using information on the nationality of the victim, we find that this increase was driven by homicides involving Venezuelan victims, with no evidence of a statistically significant increase in homicides in which Colombians were victimized. Thus, in contrast to xenophobic fears that migrants might victimize natives, it was migrants, rather than natives, who faced risks associated with immigration. Using arrests data, there is no corresponding increase in arrests for homicides in these areas. Taken together, these results suggest that the increase in homicides close to the border documented here are driven by crimes against migrants and have occurred without a corresponding increase in arrests, suggesting that some of these crimes have gone unsolved.
\end{abstract}

Keywords: Crime, Migration, Venezuela

JEL classification: J15, J18, K42

*Andrea Garcia and Diana Ricculi provided helpful research assistance. The opinions contained in this document are the sole responsibility of the author and do not commit Banco de la República or its Board of Directors.

†Brown University. Email: Brian_Knight@brown.edu

†DEPE-Banco de la Republica de Colombia. Email: Atribiur@banrep.gov.co. 


\title{
Immigration and Violent Crime: Evidence from the Colombia-Venezuela Border*
}

\author{
Brian Knight ${ }^{\dagger} \quad$ Ana Tribin ${ }^{\ddagger}$
}

\begin{abstract}
This paper investigates the link between violent crime and immigration using data from Colombian municipalities during the recent episode of immigration from Venezuela. The key finding is that, following the closing and then re-opening of the border in 2016, which precipitated a massive immigration wave, homicides in Colombia increased in areas close to the border with Venezuela. Using information on the nationality of the victim, we find that this increase was driven by homicides involving Venezuelan victims, with no evidence of a statistically significant increase in homicides in which Colombians were victimized. Thus, in contrast to xenophobic fears that migrants might victimize natives, it was migrants, rather than natives, who faced risks associated with immigration. Using arrests data, there is no corresponding increase in arrests for homicides in these areas. Taken together, these results suggest that the increase in homicides close to the border documented here are driven by crimes against migrants and have occurred without a corresponding increase in arrests, suggesting that some of these crimes have gone unsolved.
\end{abstract}

Keywords: Crime, Migration, Venezuela

JEL classification:J15, J18, K42

\footnotetext{
* Andrea Garcia and Diana Ricculi provided helpful research assistance. The opinions contained in this document are the sole responsibility of the author and do not commit Banco de la República or its Board of Directors.

${ }^{\dagger}$ Brown University. Email: Brian_Knight@brown.edu

${ }^{\ddagger}$ DEPE-Banco de la Republica de Colombia. Email: Atribiur@banrep.gov.co.
} 


\section{Introduction}

There is a long history of xenophobia, or fear of immigrants, around the world, and these negative perceptions of immigrants can apply to many different issues. Campante, Depetris-Chauvin and Durante (2020) document that the Ebola health scare in the U.S. during 2014 led to more conservative views towards immigrants. According to a 2018 survey by Quinnipiac University, 71 percent of respondents in the United States think that undocumented immigrants illegally crossing the border with Mexico is an important problem, and 37 percent think that undocumented immigrants take jobs away from American citizens ${ }^{1}$ Donald Trump recently used anti-immigration rhetoric as a key campaign theme, helping to propel him to win the 2016 Presidential Election (Lamont, Park and Ayala-Hurtado (2017)).

This paper investigates the link between immigration and violent crime based upon an analysis of crime rates in municipalities in Colombia before and after the massive immigration wave from Venezuela that occurred during the past decade. This wave has led to anti-immigrant perceptions and a backlash among natives. Based upon a survey conducted in Cucuta, a city close to a key border crossing with Venezuela, nearly two-thirds of respondents considered migrants as a threat to the city (FIP (2019)). Likewise, a national survey in Colombia found that 62 percent of respondents had an unfavorable perception of Venezuelan migrants, with only 31 percent having a favorable perception. In the same survey, 54 percent of respondents were in favor of closing the border, with only 40 percent supporting the relatively lax status quo policy $:^{2}$ Furthermore, an OxFam (2019) survey shows that 74 percent of Colombians believe that immigration increases crime and insecurity, a higher percentage than that of Ecuador (68 percent) and Peru (70 percent). Large anti-government protests in the capital city of Bogota during late 2019 further fueled anti-migrant perceptions, with wide circulation of unfounded rumors involving crimes committed by migrants during the protests. $3^{3}$ Consistent with negative perceptions about international migrants, Rozo and Vargas (2018) document that inflows of internal migrants into Colombian municipalities does not affect voting behavior, while international migration reduces support for the incumbent party and increases votes for the right-wing candidates. Exploring possible economic mechanisms behind this increase in support for right-wing parties, the authors do not find any evidence of detrimental economic effects from migration that could drive these anti-immigrant views.

In this paper, we systematically address these issues using data on crimes in Colombian municipali-

\footnotetext{
${ }^{1}$ https://poll.qu.edu/images/polling/us/us04112018_ugnt28.pdf

${ }^{2}$ See https://www.semana.com/nacion/articulo/encuesta-invamer-aumenta-el-rechazo-a-los-venezolanos/626177

${ }^{3}$ https://www.reuters.com/article/us-colombia-strike-venezuela/protests-in-colombia-spark-backlash-against-venezuelanmigrants-idUSKBN1Y516U
} 
ties. We address two specific research questions. First, has the recent immigration wave from Venezuela led to an increase in violent crime in affected regions of Colombia? Second, if so, did this increase primarily involve crimes against natives or crimes against migrants? While xenophobia around criminal activity involves perceptions of more crimes committed by immigrants against natives, there is evidence that immigrants themselves are at heightened risk for victimization $4^{4}$ Moreover, the existing literature on immigration and crime has lacked the nationality data necessary to understand which of these two views is correct. That is, do increases in crimes in areas with more migrants primarily involve crimes committed against natives or crimes committed against migrants?

To answer these research questions, we examine crime patterns in Colombia using both temporal and geographic variation. Our temporal variation involves the closing (August 2015) and subsequent reopening (August 2016) of the border with Colombia by President Maduro of Venezuela, precipitating a massive immigration wave that accelerated in 2017 and peaked in 2018. The geographic variation involves comparing municipalities closer to and further from five key border crossings along the border between Colombia and Venezuela. To answer the first research question, we use data on homicide rates by municipality and month over the period 2010-2019. To answer the second research question, we also incorporate information on the nationality of homicide victims. To better understand how and whether these crimes were resolved by police, we supplement this analysis with data on arrests for homicides.

In terms of the first research question, we do find that there was an increase in homicides in municipalities close to the five key border crossings following the closing and subsequent re-opening of the border in 2016, relative to the time period prior to the closing and relative to municipalities that lie further from these border crossings. These results are robust to using an alternative temporal definition of the migration wave, focusing on periods of hyperinflation in Venezuela, which helped to fuel the exodus to Colombia. Likewise, the results are robust to using a measure based upon travel times, rather than travel distances, and to using the distance to the two most important border crossings, rather than the distance to all five border crossings. Exploring the timing of homicides more finely, we find that the increase in crime close to the border was at its highest level during 2018, when both hyperinflation in and migration from Venezuela were also at their peak. Exploring more finely the geographic patterns of homicides, we find that the increase in homicides following the closing and subsequent re-opening of the border is driven by municipalities very close to the frontier, those within 100 miles of one of the five key border crossings.

In terms of the second research question, we find that this increase in homicides in this frontier region,

\footnotetext{
${ }^{4}$ The United Nations Refugee Agency highlights that migrants from Venezuela are often victimized (see https://www.unhcr.org/5ab8e1a17.pdf accessed July 10, 2020).
} 
following the closing and subsequent re-opening of the border, was driven by crimes against both Venezuelans and victims for whom the police did not record a nationality. We conjecture that this second category primarily involves undocumented migrants from Venezuela. We find no statistically significant evidence of an increase in homicides against native Colombians. Exploring more finely the timing of the increase in homicides against Venezuelans in the border region, we find that this increase was again the strongest during 2018, when both hyperinflation in and migration from Venezuela were at their peak. Exploring more finely the geographic patterns surrounding the increase in homicides against Venezuelans following the closing and subsequent re-opening of the border, we find that the results are driven almost exclusively by municipalities very close to the frontier, those within 100 miles of one of the five key border crossings.

Turning to data on arrests, we find no statistically significant evidence of an increase in arrests in areas close to the border following the closing and subsequent re-opening of the border. Taken together, these results suggest that the increase in homicides close to the border documented here have occurred without a corresponding increase in arrests, suggesting that some of these crimes have gone unsolved. Moreover, counter to xenophobic perceptions associated with migrants committing crimes against natives, our results appear to be driven by crimes against migrants.

The paper proceeds as follows. We next review the relevant literature and then provide a more detailed overview of the setting. We then describe our empirical approach and data. Following a presentation of our empirical results, the final section concludes.

\section{Related Literature}

A large existing literature addresses a similar research question: does immigration increase crime? Broadly speaking, the literature has used two approaches to answering this research question. The first approach uses changes in the legal treatment of already arrived immigrants in the destination country. Pinotti (2017) and Mastrobuoni and Pinotti (2015) exploit exogenous variation in legalization treatment of immigrants in Italy, finding that legalization tends to reduce both crime rates and recidivism rates. Hines and Peri (2019) and Miles and Cox (2014) study the Secure Communities program in the United States, finding that increased enforcement of immigration laws and associated deportations did not reduce crime rates in these communities.

Our paper is more closely related to the second approach, which uses immigrant shocks, in both withincountry and cross-country analyses, to study the link between immigration and crime. Butcher and Piehl 
(1998) link immigration patterns to crime rates in metro areas in the United States, finding no correlation between the two factors after controlling for local demographics in these metro areas. Spenkuch (2014) conducts a similar analysis but uses an instrumental variables approach, based upon ethnic differences in settlement patterns, finding an effect of immigration for crimes motivated by financial crime and also for those immigrants most likely to have poor labor market outcomes. In a study of crime rates in Italy, Bianchi, Buonanno and Pinotti (2012) use a similar approach based upon settlement patterns within Italy and changes in the number of migrants from origin countries to destination countries outside of Italy, finding that increased immigration leads to a small but positive increase in robberies but no change in the overall crime rate. Chalfin (2014) develops an instrument based upon rainfall shocks in Mexico, finding no link between immigration and crime in the United States. Piopiunik and Ruhose (2017) study the collapse of the former Soviet Union and the subsequent immigration of ethnic Germans to Germany. They exploit the exogenous allocation of these migrants across regions of Germany, finding significant increases in crime. Nunziata (2015) uses a split sample instrumental variables approach, finding that immigration does not increase crime rates but does lead to an increase in the fear of crime, especially among natives with unfavorable attitudes towards immigrants, consistent with a link between xenophobia and crime.

Relative to this literature, our paper makes three contributions. First, and most importantly, by exploiting incident-level crime data that includes information on the nationality of the victim, we can distinguish between crimes against immigrants and crimes against natives. As noted above, Nunziata (2015) documents that, despite no change in crime rates, natives perceive a link between immigration and crime in Europe, and, as noted above, many native Colombians tend to have unfavorable perceptions of migrants from Venezuela. Yet, countering this view, we find that the increase in violent crime in areas most affected by immigration is driven by crimes against migrants rather than by crimes against natives. Our second contribution involves the development of a new identification strategy, based upon the closing of the border by Maduro in 2015, the subsequent re-opening in 2016, and the distance to five key crossings on the border between Colombia and Venezuela. Third, while the literature has tended to focus on crime in the United States and Europe, we study South America, which tends to have much higher rates of violent crime. Recent homicide rates in Colombia and Venezuela were 25 per 100,000 and 56 per 100,000, respectively, versus rates of 5 per 100,000 in the United States and only 1 per 100,000 in both Germany and Italy 5

There is one recent paper, Franco-Mora (2020), developed simultaneously with and independently of

\footnotetext{
${ }^{5}$ These statistics are based upon World Bank data, derived from https://data.worldbank.org/indicator/VC.IHR.PSRC.P5?locations=MX (accessed July 9, 2020).
} 
this paper, that studies immigration from Venezuela and crime in Colombia. Using monthly data over the time period January 2016 to June 2108, his paper attempts to distinguish between irregular and regular migration, finding that irregular migration increases theft and that legal migration increases homicides. These two papers are different on several dimensions. First, and most importantly, we distinguish between crimes against natives and crimes against Venezuelans, documenting that the increase in violent crime is driven by crimes against migrants. This finding is inconsistent with anti-immigrant views involving crimes committed by migrants against the native population. Second, while we exploit distance to the border and the closing and subsequent re-opening of the border by Maduro, Franco-Mora (2020) uses the presence of migrants in municipalities during different points in time over this 30 -month period. Third, we study a longer time period, 2010-2019, allowing for a substantial time period prior to the migration wave.

This paper is also related to a literature on the labor market effects of the Venezuelan refugee crisis in Colombia. Bonilla-Mejia et al. (2020) analyze the extent to which immigration is responsible for increases in unemployment, finding that new migration mainly hurts the labor conditions of established migrants. That is, their results show that an increase in the share of immigrants increases the probability of unemployment for the immigrant population. On the other hand, migration does not affect the probability of unemployment of non-immigrants since employment losses are compensated by a reduction in participation. In a parallel study, Santamaria (2020) uses a differences-in-differences strategy, exploiting immigration flows and the timing of migration shocks to measure the impact of migrants on labor market outcomes in Colombia. Using google search patterns to identify immigrant host communities in Colombia, the author finds a negligible reduction in wages for both informal workers and less educated workers in the formal sector. In the same vein, Caruso, Gomez-Canon and Valerie-Mueller (2019) find that an increase in the supply of immigrant labor reduces informal sector wages in urban areas. These harmful consequences are generated mostly by male workers and are more pronounced for those in low-skilled jobs. Summarizing, these studies find a deterioration in labor market outcomes, especially for migrants, the less educated, and informal workers. These changes in labor market outcomes could represent a contributing mechanism towards changes in violent crime in affected areas.

There is also an extensive literature on crime in Colombia, driven by the fact that the country has experienced an internal war for more than five decades. Prem et al. (2018) analyzes murders of social leaders before and after the peace agreement. Idrobo, Mejía and Tribin (2014) find that the increase of illegal gold mining by illegal armed groups caused a statistically significant increase in violence, as measured by the homicide rate and the number of victims of massacres. Gaviria (2000) shows that criminal 
groups, especially drug traffickers, transformed Colombia into a more-than-suitable place for criminal activities of all sorts through congestion in law enforcement, the supply of weapons, and the creation of a culture that favors easy money and the violent resolution of conflicts. Despite this, there is scarce literature about the contribution of migration from Venezuela to crime patterns in Colombia.

\section{Institutional Context}

Venezuela has experienced an economic and political crisis during the past decade and especially so during the time period following the death of President Hugo Chavez, which occurred in 2013. Chavez was replaced by his Vice President, Nicolas Maduro, who then won two subsequent Presidential elections that were highly disputed by the opposition over claims of irregularities (Corrales (2020)). During Maduro's time as President, Venezuela has suffered an economic depression. A decline in oil prices during 2016 contributed to a significant reduction in government revenues, leading to shortages, sustained inflationary pressure, and ultimately episodes of hyperinflation (Hernandez and Monaldi (2016)). All told, the economy is estimated to have shrunk by two-thirds between 2013 and 2019.6 Massive protests over economic and political issues occurred in the country, with significant events occurring in both 2017 and 2019.

By the end of 2019, due to this political and economic crisis, more than 4 million Venezuelans had left their country, out of an estimated population of 28 million in 2010, representing one of the largest migration waves ever. $]^{7}$ Given its long and relatively open border, Colombia has been disproportionately affected, with roughly 1.8 million Venezuelan migrants living in Colombia, a country with a population of roughly 50 million, by the end of 2019.8 The Colombian government has managed this challenging situation by providing timely border assistance, relaxing entry requirements, granting temporary permits, and ensuring universal emergency care (OECD (2019)). Of the 1.8 million migrants, a minority (roughly 750,000) are considered to be in legal status with an Special Stay Permit (Permiso Especial de Permanencia or PEP), with the majority (just over one million) in an irregular situation, having exceeded their allowed residence time or entered without authorization 9

Based upon author calculations using the 2019 Great Integrated Household Survey (GEIH), migrants

\footnotetext{
${ }^{6}$ https://www.economist.com/the-americas/2020/03/19/a-tale-of-two-crises-in-colombia

${ }^{7}$ https://www.unhcr.org/en-us/venezuela-emergency.html

${ }^{8}$ https://www.migracioncolombia.gov.co/infografias/total-de-venezolanos-en-colombia-corte-a-31-de-diciembre-de-2019 (accessed July 8, 2020).

${ }^{9}$ The PEP was introduced in 2017 in response to the influx of displaced Venezuelans. It is valid for 90 days at a time, automatically renewable for up to two years, and is by the government of Colombia at no cost.
} 
from Venezuela residing in Colombia tend to be younger than natives. While 17 percent of natives are between ages 20 and 29, this age group represents 26 percent of migrants. 24 percent of migrants also have children under the age of 9, compared to 17 percent among natives. At the other end of the age spectrum, only 2 percent of migrants are over over 65 years old, relative to 9 percent of natives. While many migrants were male during the early stages of the migration wave, males and females were equally represented in the survey by 2019. Most migrants participate in the labor market but tend to have lower incomes than natives and also experience high levels of informality (Tribin-Uribe et al. (2020 forthcoming)).

As mentioned above, our research design uses both temporal and geographic variation. Regarding temporal variation, we exploit the closing of the border by Maduro in August 2015 and the subsequent re-opening one year later. During August 2015, there was a conflict along the border in which three Venezuelan soldier were injured by gunfire. This conflict led President Maduro to close the border with Colombia, along with the deportation of some Colombians from Venezuela. One year later, during August 2016, the border was re-opened. ${ }^{10}$ As shown in Figure 1, the closing led to a substantial decline in border crossings over this period when the border was closed, from August 2015 to July 2016, relative to the prior years, from 2012 to mid-2015. Likewise, there was a a large jump in border crossings when the border was re-opened in August 2016. Border crossing remained at elevated levels over the next year, before spiking further in 2018 , with roughly 100,000 crossings per month at the peak. These spikes coincide with both political turmoil, as represented by protest activity, and economic turmoil, as represented by hyperinflation in Venezuela, which, according to official government figures, reached its highest rate of inflation of 130,060 percent during calendar year 2018.11

Regarding geographic variation, Colombia and Venezuela share a land border of nearly 1,400 miles, and we focus our research on the location of five key border crossings, listed from north to south, and as shown in Figure 3: Maicao, Puerto Santander, Cucuta, Arauca, and Puerto Carreno ${ }^{12}$ As shown in Figure 2, based upon official border crossings data, Cucuta is the location with the most crossings, resulting from the Cucuta border crossing being located on the Simon Bolívar International Bridge, which links key highways originating in Caracas, the largest city in Venezuela, to key highways that ultimately lead to Bogota, the largest city in Colombia 13 Maicao is the location with the second most crossings, resulting from its close proximity to Maracaibo, the second largest city in Venezuela, and several large metro areas

\footnotetext{
${ }^{10} \mathrm{https}: / /$ www.bbc.com/news/world-latin-america-37072433 (referenced June 30, 2020)

${ }^{11} \mathrm{https} / / /$ en.wikipedia.org/wiki/Hyperinflation_in_Venezuela\#Inflation_rate (accessed June 30, 2020).

${ }^{12}$ There are also an undetermined number of informal crossings, with migrants paying smugglers to cross illegally. See, for example, https://www.npr.org/2019/04/04/709193469/chronicles-of-a-venezuelan-exodus-more-families-flee-the-crisis-onfoot-every-da

${ }^{13}$ These data can be accessed from the website https://public.tableau.com/profile/migraci.n.colombia\#!/.
} 
in the north of Colombia. The next largest crossing is Puerto Santander, which is located just north of the crossing at Cucuta. The other two crossings, Arauca and Puerto Carreno, are located further to the eastern part of Colombia and in more rural areas. These two border crossings have a small number of migrants during the time period analyzed here, 2012-2019.

To document a link between border crossings and immigration, we next examine the geographic spread of migrants from Venezuela in Colombia using 2005 and 2018 Census data on the fraction of the population in Colombian municipalities who were born in Venezuela $\sqrt{14}$ As shown in Figure 3, which plots deciles of the percentage point change in the fraction born in Venezuela between 2005 and 2018, there are overall increases in fraction of the population that was born in Venezuela, ranging across municipalities from no increase or a small increase to an increase of 23 percentage points. More importantly for our research design, the largest increases are clustered near the land border with Venezuela, with especially large increases in areas close to the five key border crossings.

\section{Approach and Data}

As described above, our empirical approach relies on both temporal and geographic variation. Regarding the temporal variation, we exploit timing surrounding the closing and re-opening of the border in August 2016. As documented above, this reopening led to a spike in the number of migrants crossing the border. Regarding the spatial variation, we measure the distance between each municipality and the five key border crossings. As documented above, the newly arrived migrants tended to settle in areas close to the border and especially so in municipalities that are close to the five key border crossings.

To measure geographic exposure to migration, we first calculate both the travel distance and the travel time between each municipality urban center and each of the five border crossings. This is implemented using the Google Maps API. In particular, the latter returns information on travel distance and travel time based on the recommended route between start and end points, as calculated by Google Maps. Given that a departure time is not specified, choices of route and duration are based on the road network and average travel time, independent of traffic conditions. We then collapse travel distance, and analogously for travel time, to a single measure of exposure to Venezuelan migrants for each municipality by computing the distance between each municipality and the closest border crossing. That is, we compute the minimum

\footnotetext{
${ }^{14}$ The Census official statistics, derived from the National Administrative Department of Statistics (DANE), estimate the total population in Colombian municipalities by nationality at two points in time: 2005, before the influx of migrants from Venezuela, and 2018, which is close to the end of the peak of the migration wave.
} 
distance to a border crossing for each municipality and likewise for travel times.

Throughout the empirical analysis, we estimate the following regression model:

$$
h_{m t}=\alpha_{m}+\alpha_{t}+\beta \text { After }_{t} \times \ln \left(\text { distance }_{m}+\varepsilon_{m t}\right.
$$

where $h_{m t}$ represents the homicide rate in municipality $m$ during month $t, \alpha_{m}$ represents municipality fixed effects, $\alpha_{t}$ represents month-by-month fixed effects, After ${ }_{t}$ indicates the time period following the reopening of the border in August 2016, $\ln (\text { distance })_{m}$ represents travel distance between the municipality and the closest border crossing, and $\varepsilon_{m t}$ represents unobserved factors. Our key parameter of interest, $\beta$, captures the change in the homicide rate as a function of distance to the border following the re-opening of the border in August 2016, relative to the prior time period. Given that our measure of distance is small close to the border and larger further from the border, we hypothesize a negative coefficient. That is, following the re-opening of the border, we hypothesize that homicides should fall as distance from the border increases.

To measure homicides, we use administrative records in our analysis. The National Police of Colombia provide the data on reported crimes and arrests ${ }^{15}$ The crime data are based on incidents and specify the exact municipality, date, nationality of the victim, and type of reported crime. Similar measures are available for arrests data, with nationality pertaining to that of the arrested individual rather than to that of the victim. These data are available from 2010 to 2019, and we aggregate these to the municipalitymonth level. We focus on homicides, a measure that does not suffer from self-reporting problems and is not subject to two important changes in the methodology in crime reporting that occurred in the past few years, during the crucial periods of immigration. 16

Our measure of homicides rates requires not only a count of homicides but also an annual measure of population. Towards this end, we use official population data from the National Administrative Department of Statistics (DANE). DANE made population projections at the national and regional level over the 2005-2020 period. These projections were based on the adjusted results of the 2005 Census and the 1985 to 2005 census reconciliation.

In alternative specifications, we use measures of the consumer price levels and corresponding inflation

\footnotetext{
${ }^{15}$ Crime data were downloaded directly from the the national police web page (https://www.policia.gov.co/grupoinformaci\%C3\%B3n-criminalidad/estadistica-delictiva) and arrests data were provided through a right of petition.

${ }^{16}$ Starting in In 2017, the Nation Attorney General's Office and the National Police integrated their information. Homicide crime in both databases had 98 percent degree of coincidence. Around the same time, the national police introduced a mobile phone app for reporting certain crimes, leading to a surge in newly reported crimes. Importantly, the mobile app did not apply to homicides, given their severity. For more information about these changes in methodology, see Rodriguez-Ortega et al. (2018).
} 
rate from Venezuela in place of an indicator for the period after the re-opening of the border in August 2016. These data on prices and inflation are available at the monthly level starting in 2008 and are based upon the National Consumer Price Index (INPC), as published by the Central Bank of Venezuela ${ }^{17}$ As shown in Figure 4, inflation began rising during 2017, with further increases in 2018, peaking at a monthly inflation rate of almost 200 percent in January 2019. Comparing this series of inflation rates to the monthly series of border crossings in Figure 1, there is a clear link between the emergence of hyperinflation and the wave of immigration from Venezuela into Colombia 18

\section{Crime Results}

Before presenting our formal regression results, we first provide evidence on the change in the average monthly homicides rate in the form of a map of municipalities in Colombia. The change in the homicides rate compares the time period after the re-opening of the border in (that is, from August 2016 to December 2019) to the time period before the re-opening of the border (that is, from January 2010 to July 2016). As shown in Figure 5, there is a clear increase in homicides close to the border and especially so in municipalities that are in close proximity to the five key border crossings. Yet, the results are noisy in general, with large increases in homicide rates in municipalities further from the border as well. Given this, we next measure both the magnitude and statistical significance of these relationships in a regression analysis.

We begin by presenting regression results that analyze the change in the homicides rate as function of distance to the frontier, comparing the time period following the re-opening of the border in August 2016 to the prior period. As shown in column 1 of Table 1, we find the hypothesized negative coefficient on the interaction between distance and the indicator for the time period following the re-opening of the border, and this relationship is statistically significant at the 95 percent level. That is, municipalities close to the border experienced an increase in crime, relative to municipalities further from the border, following the re-opening of the border, relative to the prior period. Regarding the magnitude of the relationship, a doubling of distance, from, say 100 miles from the border to 200 miles from the border, is associated with a reduction in the homicides rate equal to 1.39 homicides per million residents per month. This represents a decline in the homicide rate of almost 7 percent relative to the sample average homicides rate of 20.29. Thus, the re-opening of the border led to an increase in violent crime in border areas, relative to areas

\footnotetext{
${ }^{17}$ These data were downloaded from http://www.bcv.org.ve/estadisticas/consumidor (last accessed July 3, 2020).

${ }^{18}$ In a similar vein, Bonilla-Mejia et al. (2020) uses the interaction between the share of Venezuelans living in each city in 2005 and the Venezuelan CPI to instrument migration.
} 
further from the frontier, and this increase is both statistically and economic significant in magnitude.

In the remaining columns of Table 1, we decompose the change in the homicides rate according to the nationality of the victim, with total population in the municipality remaining as the denominator. As shown, while there is a negative coefficient for Colombian victims, it is small in magnitude, with a reduction of 0.5213 homicides per million, representing only 38 percent of the total reduction in the homicides rate of -1.3865 in column 1 . The effect for Venezuelan victims, by contrast, has the hypothesized negative coefficient and is statistically significant at the 95 percent level. While the negative sign on the interaction term for Venezuelan victims is unsurprising, given the large increase in the sheer number of Venezuelans living close to the border, as documented previously in Figure 3, the magnitude of this effect is more compelling, with a reduction of 0.6387 homicides per million, representing almost one-half of the total reduction in the homicides rate of -1.3865 in column 1 . There is no effect for victims from other countries but a negative and statistically significant coefficient for victims for whom the police did not record a nationality. While we lack formal evidence on this point, we conjecture that many of these victims with missing nationality lacked identification cards and were undocumented immigrants from Venezuela. Thus, counter to negative perceptions of migrants held by some natives, the increase in crime close to the border was driven by homicides against migrants rather than homicides against natives.

While our baseline measure in Table 1 is based upon a simple indicator for the re-opening of the border in August 2016, we next investigate the timing of these effects in more detail. In particular, we next estimate the following regression model:

$$
h_{m t}=\alpha_{m}+\alpha_{t}+\beta_{y} \times \ln (\text { distance })_{m}+\varepsilon_{m t}
$$

where $y$ indexes years. This regression equation is similar to our baseline regression equation, but, instead of using information on the exact timing surrounding the closing of the border, we instead allow the coefficient on distance to vary in a flexible manner, year by year, with the effect normalized to zero in the first year of our data (2010). That is, we do not incorporate any information regarding the timing of the border opening into this specification. As shown in Figure 6, which displays the key coefficients and the corresponding 90 and 95 percent confidence intervals, there are no statistically significant changes in the role of distance during the time period from 2011 to 2016, relative to the baseline year of 2010. The negative and statistically significant effect documented in Table 1 first emerges in 2017, the first full year following the border re-opening in August 2016. That is, there is a relative increase in homicides close to the border in 2017, relative to the baseline year of 2010 and relative to municipalities that are 
situated further from the frontier. Moreover, the documented negative relationship between distance and the homicide rates is strongest in 2018, approximating the timing of the arrival of migrants documented in Figure 1, which also peaked in 2018. In summary, the timing of the change in the homicides rate, as documented in our baseline regression in Table 1, corresponds to the timing of the border opening and the subsequent arrival of migrants from Venezuela.

When focusing on Colombian victims, as shown in Figure 7, there is no evidence of a statistically significant relationship between distance and homicide rates, relative to the baseline year of 2010, and this is the case for all of the years both before and after the closing of the border in 2016. Thus, similarly to our baseline results in Table 1, the documented relationships between distance and the homicide rate are not driven by Colombian victims. Figure 8 reproduces these results for victims from Venezuelan, documenting a lack of pre-trends prior to 2016 but strong relationships between distance and homicide rates beginning in the year after the border re-opening (2017) and again peaking in 2018, the year with the most migrants arriving from Venezuela. Results for victims from other countries are noisy (Figure 9), with no strong evidence of a year-by-year relationship between homicides and distance to the border. When focusing on victims with missing nationality, the results are again noisy. Some negative relationships between distance and homicide rates occur for these victims with missing nationality following the border re-opening in 2016, with a relationship that is statistically significant at the 90 percent level during 2019, the final year of our sample.

While our baseline measure of geography in Table 1 assumed a linear relationship between the homicide rate and log distance, we next investigate more fully the geographic patterns underlying these results. In particular, we estimate the following regression model, in which the effects of the border re-opening in August 2016 are measured separately for 100-mile distance bins:

$$
h_{m t}=\alpha_{m}+\alpha_{t}+\beta_{b i n} A f t e r_{t}+\varepsilon_{m t}
$$

where the effect for the 9th distance bin, those municipalities that are furthest from the frontier (800 to 900 miles to the closest border crossing), is normalized to zero. Thus, this specification allows for a more flexible relationship between distance and the homicides rate before and after the closing and re-opening of the border in August 2016.

The results for all victims is displayed in Figure 11. As shown, the only positive and statistically significant increase in homicides following the re-opening of the border in August 2016 is for municipalities very close to the border, those within 100 miles. This is consistent with the patterns in Figure 1 , which 
documented strong clustering of migrants very close to the five border crossings between Venezuela and Colombia. Regarding the magnitude, this represents an increase of approximately 5 homicides per million, an increase of roughly 25 percent relative to the sample average homicides rate of 20.29.

In the remaining figures, we decompose this effect into homicides for victims of differing nationalities. When analyzing homicide rates for victims with Colombian nationality, as shown in Figure 12, the effect for the first border bin is positive but smaller in magnitude, relative to the effect in Figure 11, and is statistically insignificant. Thus, similarly to our baseline results in Table 1, the documented relationship between distance to the frontier, the opening of the border, and homicides rate is not driven by Colombian victims. For Venezuelan victims, by contrast, there is a very sharp increase in homicides close to the border, representing an increase of roughly 2.5 homicides per million, as shown in Figure 13, and this result is statistically significant at conventional levels. There are also statistically significant increases in the next two distance bins, representing municipalities between 100 and 200 miles and between 200 and 300 miles from the nearest border crossing, but these effects are much smaller in magnitude. There is no such spatial relationship for victims from other countries, as shown in Figure 14. For victims with missing information on nationality, we document no statistically significant increases in municipalities very close to the border but larger increases in the next two bins, representing municipalities between 100 and 200 miles and between 200 and 300 miles from the closest border crossing. While lacking formal evidence on this point, we again conjecture that these might be illegal migrants from Venezuela who lack documentation and who have moved a bit further inside Colombia.

While our baseline temporal measure is based upon a similar indicator following the re-opening of the border in August 2016, we next develop an alternative measure based upon the inflation rate in Venezuela. As noted above, the month-by-month inflation series indicated hyperinflation during this period, peaking in late 2018 and early 2019. As shown in Table 2, the results are qualitatively similar to those in Table 1 , with a statistically significant shift in the relationship between distance and the overall homicides rate during months with very high inflation rates. That is, there is a relative increase in homicides in Colombian municipalities close to the frontier with Venezuela and during periods of high inflation, relative to municipalities further from the frontier and during time periods of lower inflation. As shown in the remaining columns, there is not a statistically significant relationship for Colombian victims, and these results are again driven by Venezuelan victims and those victims for whom the police did not report a nationality. Quantitatively, the evidence with respect to Venezuelan victims is even stronger, with the coefficient of 1.1396 on the interaction between distance and inflation in column 3, representing 67 percent of the overall effect of -1.7061 in column 1. Conversely, the coefficient on the interaction between distance and inflation 
for Colombian victims equals -0.1968 , as shown in column 2, representing only 12 percent of the overall effect in column 1 .

Table 3 presents similar results to those in Table 2 but uses the log of the price level rather than the inflation rate. This measure might better account for the fact that migrants who tend to arrive from Venezuela during periods of high inflation might remain in Colombia even after the inflation rates have fallen back to lower levels, as happened during the middle and end of 2019, as previously shown in Figure 4. As shown in Table 3, the results are similar to those in Tables 1 and 2, with a statistically significant relationship between the homicide rate and the interaction between distance and the price level, and this relationship is again driven by homicides involving Venezuelan victims and those with missing nationality information. There is again no statistically significant evidence of a relationship between homicide rates for Colombians and the interaction between the price level and distance, and thus the increase in crime during period with high price levels is driven by homicides against Venezuelans and those with missing nationality.

We next present results from two robustness checks on our baseline measure of distance to the nearest of the five border crossings, as described above. The first robustness check accounts for the fact, as previously documented in Figure 2, that the number of crossings in the official data are driven in large part by two key border crossings that link important highways in Colombia and Venezuela: Maicao and Cucuta. As shown in Table 4, our results are similar when defining distance to the border as the minimum distance to Maicao and Cucuta, with slightly stronger magnitudes in column 1 of Table 4, when compared to the results in column 1 of Table 1. Regarding the nationality of victims, the results based upon these two border crossings are again only statistically significant for victims from Venezuela and those victims with missing information on nationality, with no evidence of a statistically significant increase for homicides of native Colombians. Thus, our results are robust to this alternative measure and are even a bit stronger, suggesting that our baseline results are driven by these two most significant border crossings.

Our second robustness check is based upon a measure of travel times, rather than travel distance. This measure, as noted above, does not account for traffic but does account for speed limits. In particular, we measure travel time from each municipality to each of the five border crossings and then take the minimum such time for each municipality across these five crossings. As shown in Table 5, the results are broadly similar to those in our baseline results in Table 1 . The key coefficient in column 1 is a bit smaller in magnitude but remains statistically significant at the 90 percent level. Regarding the nationality of victims, the results based upon travel times are again only statistically significant for victims from Venezuela and those victims with missing information on nationality, and the result is statistically insignificant when 
considering homicides against native Colombians. Thus, our results are robust to this alternative measure of the exposure of municipalities to the frontier with Venezuela.

To better understand how these homicide cases are adjudicated by authorities, we next analyze data on the geographic and temporal pattern of arrests for homicides. These data do not include information on the nationality of the victim but do include information on the nationality of the individual arrested for the crime, and there are not missing nationalities in this case. While we cannot directly link these arrests incidents data to the crime incidents data, we do aggregate them in a similar manner, at the level of the municipality-month. As shown in Table 6, we find no statistically significant change in the relationship between distance and arrest rates following the re-opening of the border in August 2016. As shown in column 3, we do find some evidence of an increase in arrests of Venezuelans close to the border, as should be expected given the very large increase in their presence close to the border. But there is no increase in arrests of Colombians or those from other countries, as shown in columns 2 and 4. Taken together, the results on homicides in Table 1 and the results on arrests for homicides in Table 6 suggest that these homicides close to the border have occurred without a corresponding increase in arrests, suggesting that some of these crimes go unsolved.

\section{Conclusion}

In this paper, we have brought new data and a new setting to a classic question regarding the relationship between immigration and crime. Our first research question involved the relationship between migration and crime, and the key finding here is that homicide rates increased in areas close to the border with Venezuela following the closing and then re-opening of the border in 2016. Thus, immigration of Venezuelans is associated with an increase in crime rates in the receiving municipalities. Our second research question involves addressing whether this increase in homicide rates is driven by homicides against immigrants or homicides against native Colombians, as might be expected by those with xenophobic viewpoints regarding crime. Using information on the nationality of the victim, we find that the increase in the homicide rate was driven by homicides involving Venezuelan victims, with no evidence of a statistically significant increase in homicides involving native Colombians. This is consistent with migrants being victimized and is inconsistent with xenophobic perceptions associated with migrants committing crimes against natives. Given all of this, it is important, from an academic perspective, to account for the nationality of victims when analyzing the link between crime and immigration. Using arrests data, we find no corresponding increase in arrests for homicides in these areas. In summary, our results document 
an increase in homicides in municipalities close to the border, an effect driven by homicides of migrant Venezuelans rather than homicides of native Colombians. 


\section{References}

Bianchi, Milo, Paolo Buonanno and Paolo Pinotti. 2012. "Do immigrants cause crime?" Journal of the European Economic Association 10(6):1318-1347.

Bonilla-Mejia, Leonardo, Leonardo F. Morales, Didier Hermida-Giraldo and Luz Florez. 2020. The Labor Market of Immigrants and Non-Immigrants Evidence from the Venezuelan Refugee Crisis . Borradores de Economia. 1119 Cetral Bank of Colombia Cetral Bank of Colombia: .

Butcher, Kristin F and Anne Morrison Piehl. 1998. "Cross-city evidence on the relationship between immigration and crime." Journal of Policy Analysis and Management: The Journal of the Association for Public Policy Analysis and Management 17(3):457-493.

Campante, Filipe R, Emilio Depetris-Chauvin and Ruben Durante. 2020. The Virus of Fear: The Political Impact of Ebola in the US. Technical report National Bureau of Economic Research.

Caruso, German, Christian Gomez-Canon and Valerie-Mueller. 2019. "Spillover effects of the Venezuelan crisis: migration impacts in Colombia." Oxford Economic Papers .

Chalfin, Aaron. 2014. "What is the contribution of Mexican immigration to US crime rates? Evidence from rainfall shocks in Mexico." American Law and Economics Review 16(1):220-268.

Corrales, Javier. 2020. "Democratic backsliding through electoral irregularities: The case of Venezuela." European Review of Latin American and Caribbean Studies 109:41-65.

FIP. 2019. Seguridad ciudadana y migración venezolana: Análisis exploratorio. Technical report Fundación Ideas para la Paz Bogotá, Colombia: . 
Franco-Mora, Juan Sebastián. 2020. ¿Los sospechosos de siempre? Efectos de la migración irregular en la criminalidad. Documentos CEDE 2020-8 Universidad de los Andes Bogotá, Colombia:

Gaviria, Alejandro. 2000. "Increasing returns and the evolution of violent crime: the case of Colombia." Journal of development economics 61(1):1-25.

Hernandez, Igor and Francisco Monaldi. 2016. Weathering Collapse: An Assessment of the Financial and Operational Situation of the Venezuelan Oil Industry. Technical report Center for International Development at Harvard University USA: .

Hines, Annie Laurie and Giovanni Peri. 2019. “Immigrants' deportations, local crime and police effectiveness." IZA Discussion Paper .

Idrobo, Nicolás, Daniel Mejía and Ana María Tribin. 2014. "Illegal gold mining and violence in Colombia." Peace Economics, Peace Science and Public Policy 20(1):83-111.

Lamont, Michele, Bo Yun Park and Elena Ayala-Hurtado. 2017. “Trump’s Electoral Speeches and His Appeal to the American White Working Class.” British Journal of Sociology 68:S153-S180.

Mastrobuoni, Giovanni and Paolo Pinotti. 2015. "Legal status and the criminal activity of immigrants." American Economic Journal: Applied Economics 7(2):175-206.

Miles, Thomas J and Adam B Cox. 2014. “Does immigration enforcement reduce crime? evidence from secure communities." The Journal of Law and Economics 57(4):937-973.

Nunziata, Luca. 2015. "Immigration and crime: Evidence from victimization data." Journal of Population Economics 28(3):697-736.

OECD. 2019. OECD Policy Note on the Venezuelan migration shock in Colombia and its fiscal implications. Policy note OECD France: . 
OxFam. 2019. YES, BUT NOT HERE. Perceptions of xenophobia and discrimination towards Venezuelan migrants in Colombia, Ecuador and Peru. Technical report OxFam International.

Pinotti, Paolo. 2017. “Clicking on heaven's door: The effect of immigrant legalization on crime.” American Economic Review 107(1):138-68.

Piopiunik, Marc and Jens Ruhose. 2017. "Immigration, regional conditions, and crime:

Evidence from an allocation policy in Germany." European Economic Review 92:258-282.

Prem, Mounu, Andrrs Rivera, Dario Romero and Juan F. Vargas. 2018. “Killing Social

Leaders for Territorial Control: The Unintended Consequences of Peace.” SSRN Electronic Journal .

Rodriguez-Ortega, Jair David, Daniel Mejia-Londono, Lorena del Pilar Caro-Zambrano, Romero-Hernandez Mauricio and Franney Campos-Mendez. 2018. "Implications of the integration process of the administrative records of criminality between the SPOA (Oral Accusatory Criminal System) of the Attorney General's Office (FGN) and the SIEDCO (Statistical, Delinquency, Offenses and Operations Information System) of the National Police of Colombia (PONAL), and the implementation of the ; ADenunciar! app on crime figures." Revista Criminalidad 60:9 - 27.

Rozo, Sandra and Juan F. Vargas. 2018. Brothers or Invaders? How Crisis-driven Migrants Shape Voting Behavior. Working paper LACEA. Documentos de Trabajo LACEA 016836.

Santamaria, Julieth. 2020. Venezuelan Exodus": The Effect Of Mass Migration On Labor Market Outcomes PhD thesis University of Minnesota Minneapolis MN: .

Spenkuch, Jörg L. 2014. "Understanding the impact of immigration on crime." American law and economics review 16(1):177-219.

Tribin-Uribe, Ana M., Andrea Otero, Didier Hermida, Jorge Ramos, Jose Pulido, Leonardo Bonilla, Leonardo Morales, Ligia Melo, Luz A. Florez, Francisco Lasso, Jorge Tamayo, Juan C. Castro, Carlos Medina, Juan J. Ospina-Tejeiro, Franz Hamann-Salcedo, Oscar 
Avila-Montealegre, Juan C. Castro-Fernandez, Anderson Grajales-Olarte, Juan C.

Mendez-Vizcaino, Mario Ramos-Veloza, Alexander Guarin-Lopez, Gaurav Khanna, Anant Nyshadam and Santiago Velasquez. 2020 forthcoming. ESPE sobre Efectos de la Migracion desde Venezuela. Revista ESPE - Ensayos sobre Politica Economica. Banco de la Republica de Colombia. Bogota, Colombia: . 


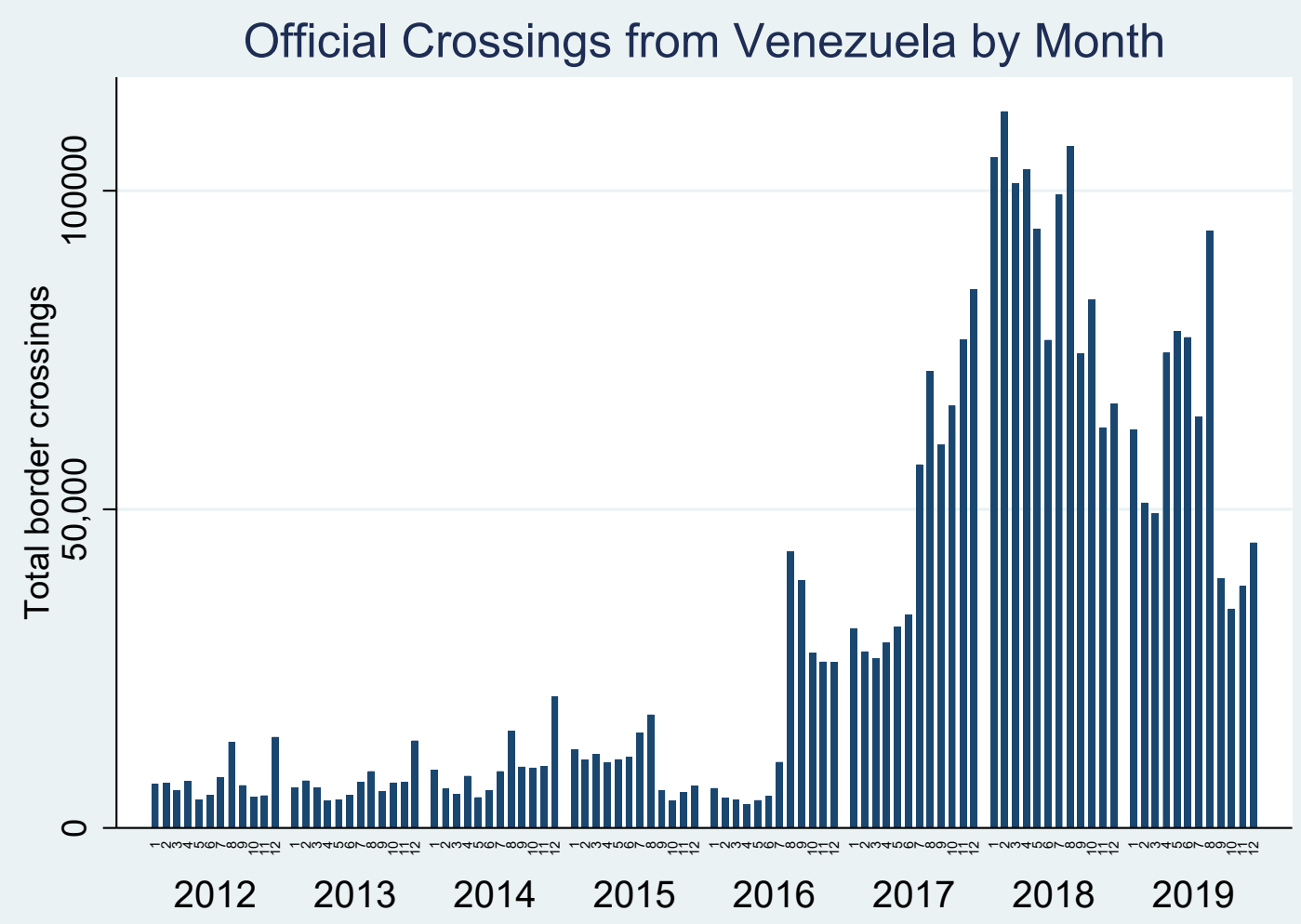

Figure 1

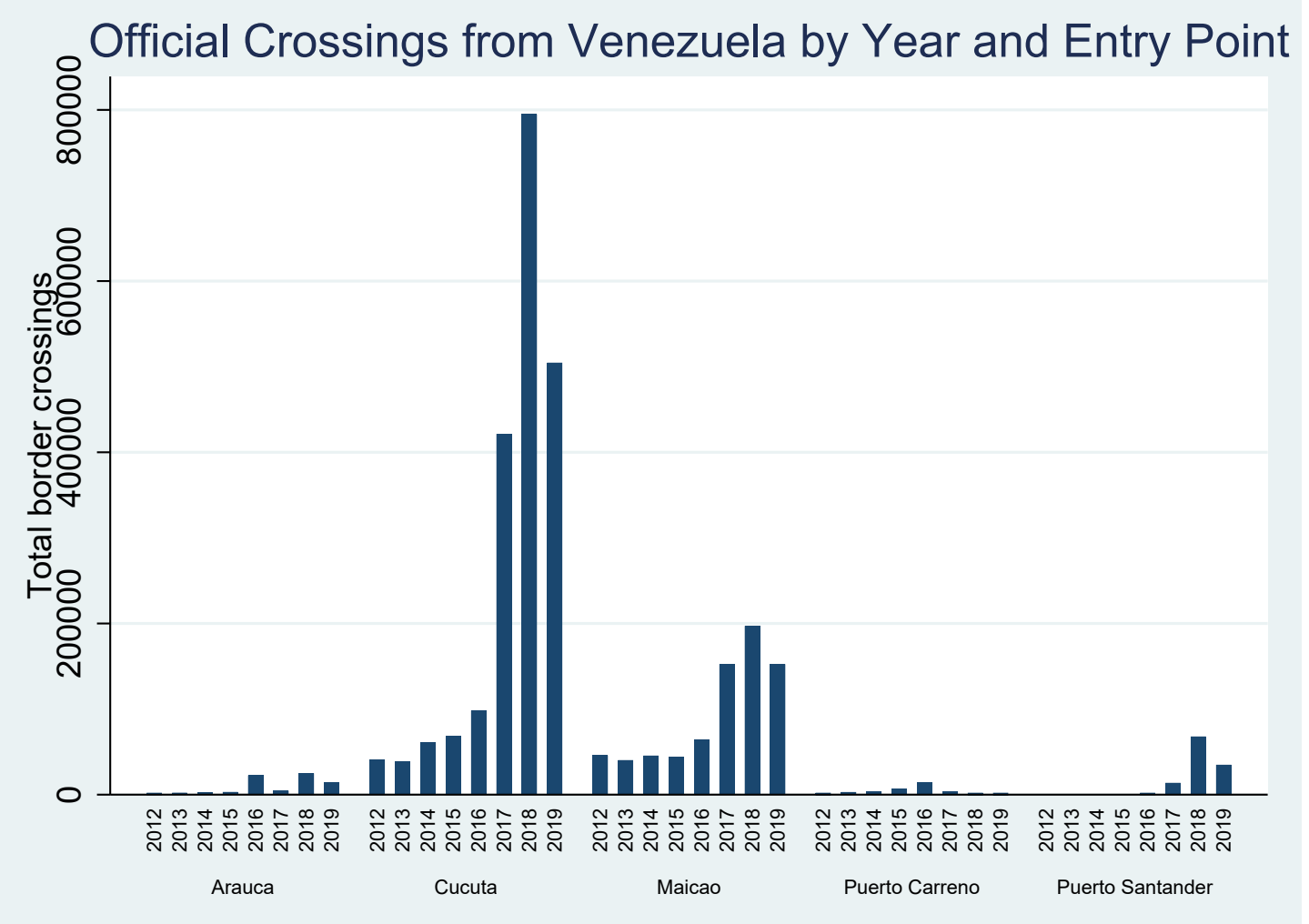

Figure 2 


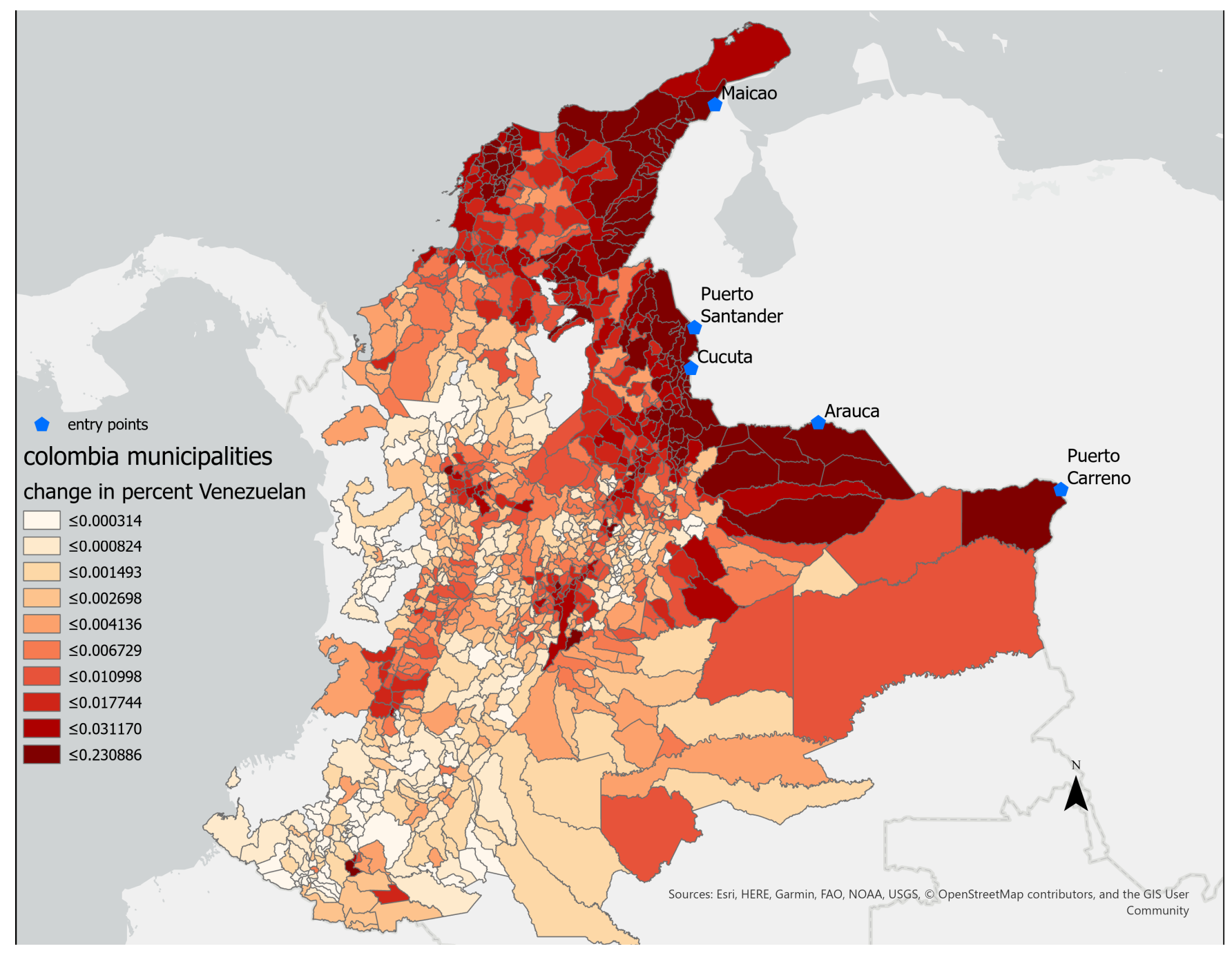

Figure 3: Change in Percent Venezuelan: 2005-2018 


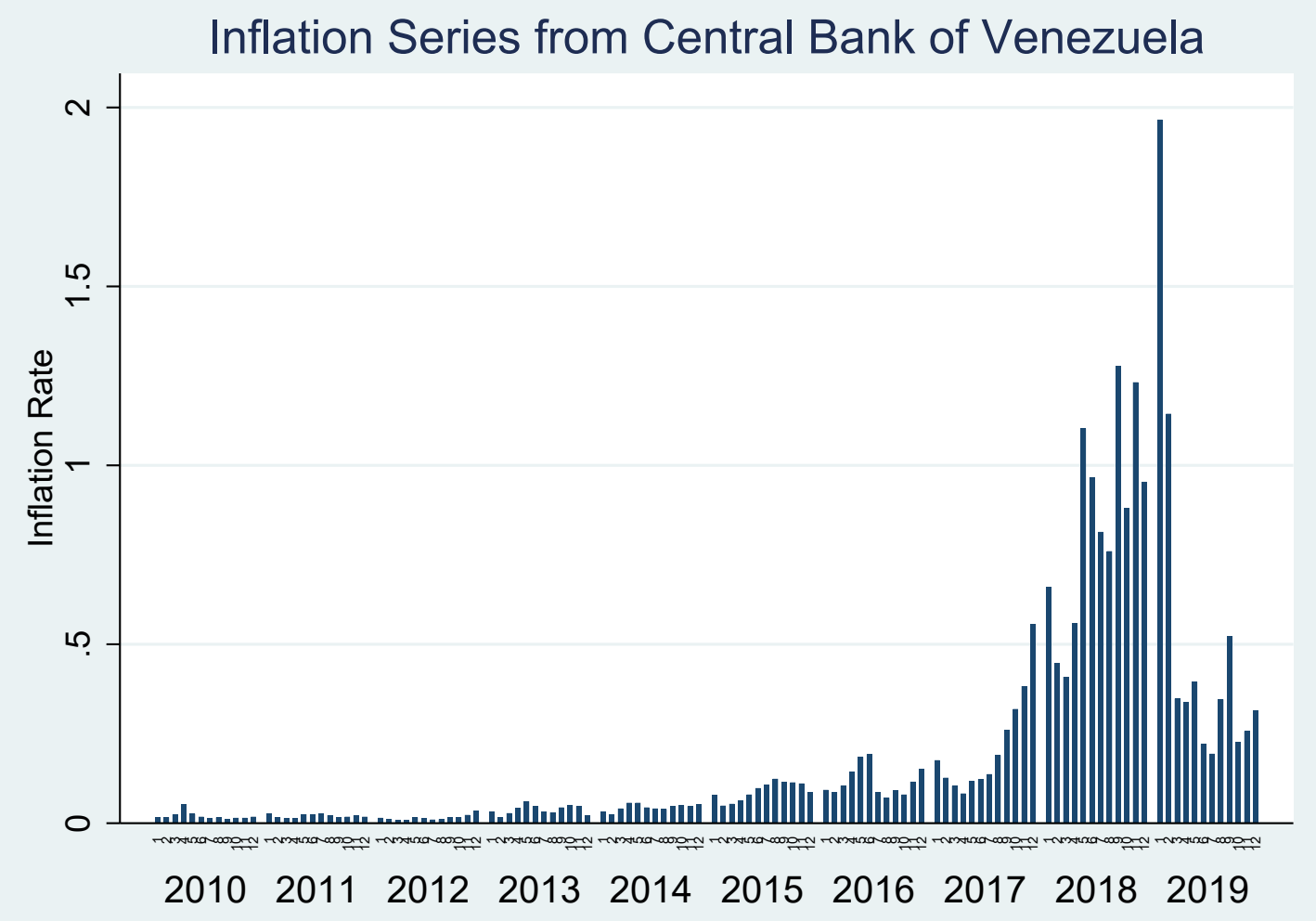

Figure 4 


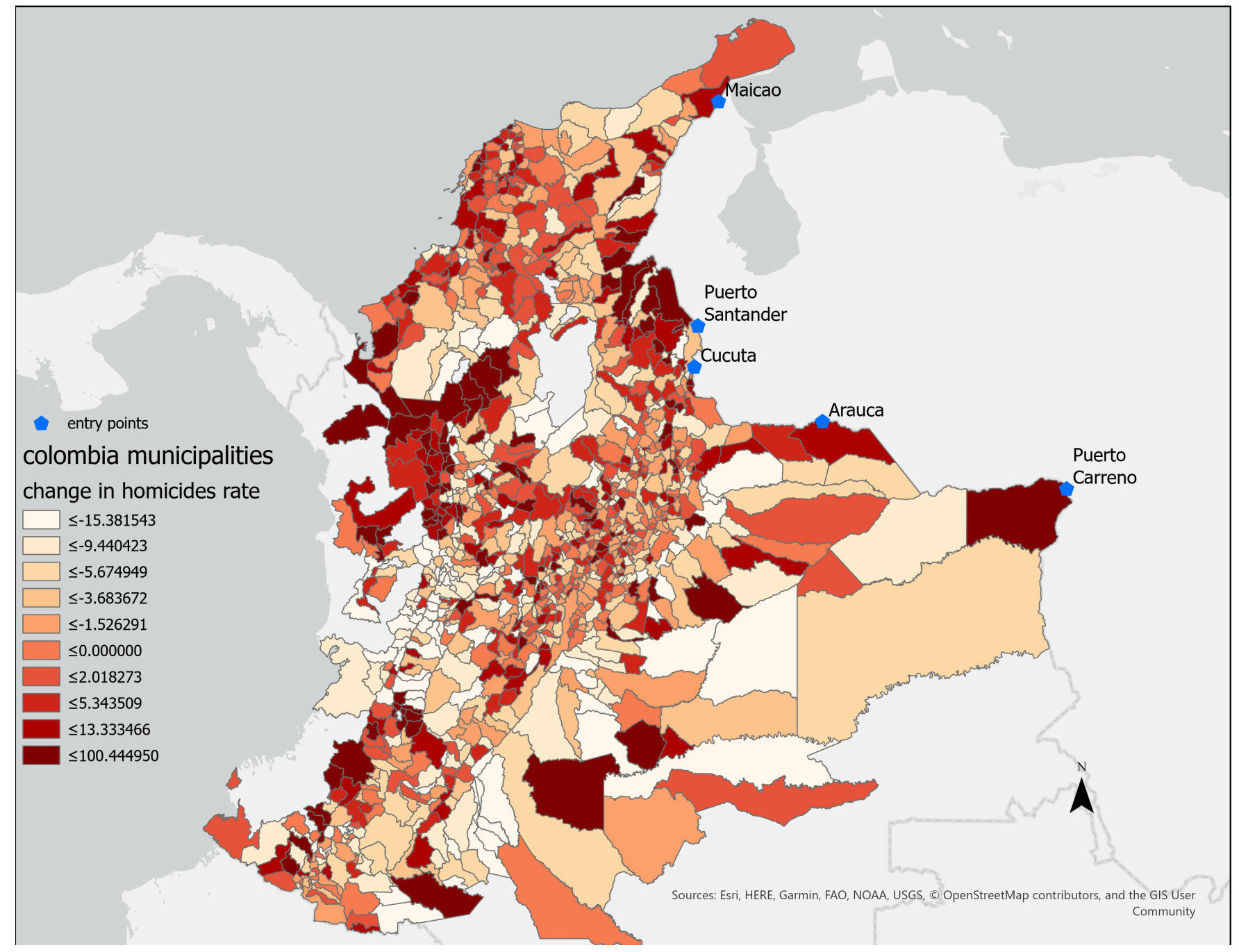

Figure 5: Change in Homicides Rate after Border Opening 
Effects of Distance from Border by Year

TOTAL

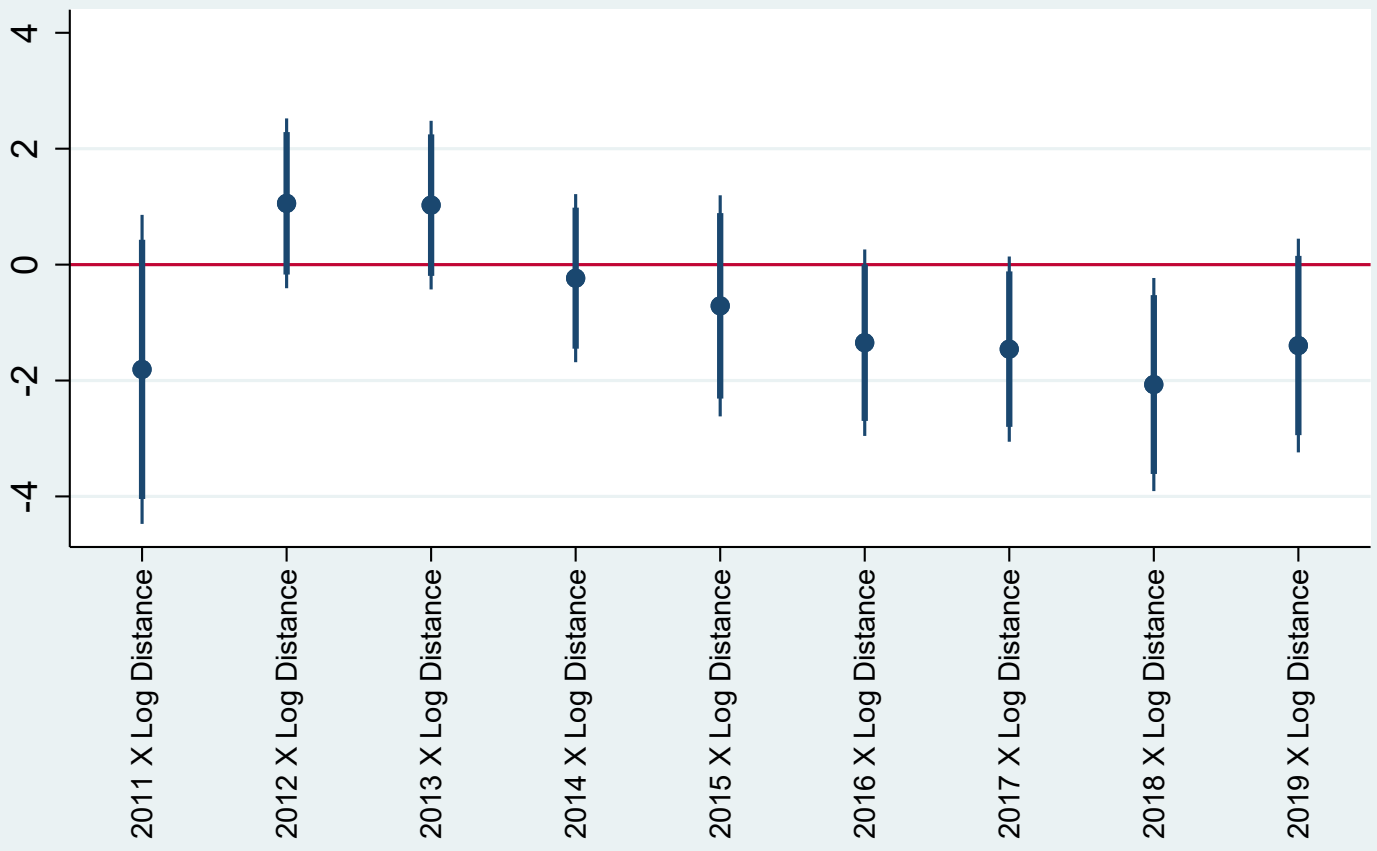

Figure 6

Effects of Distance from Border by Year COLOMBIA VICTIMS

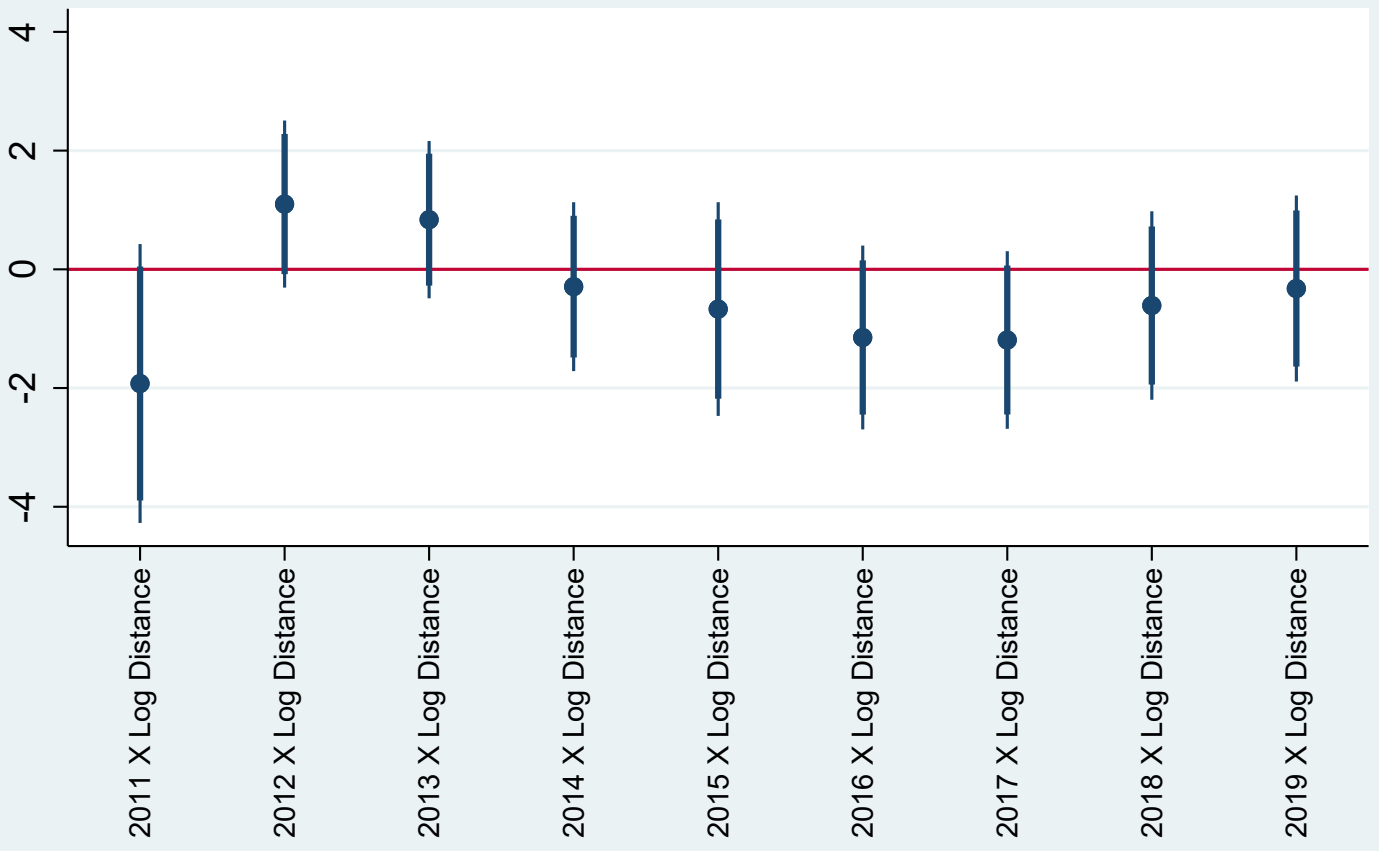

Figure 7 


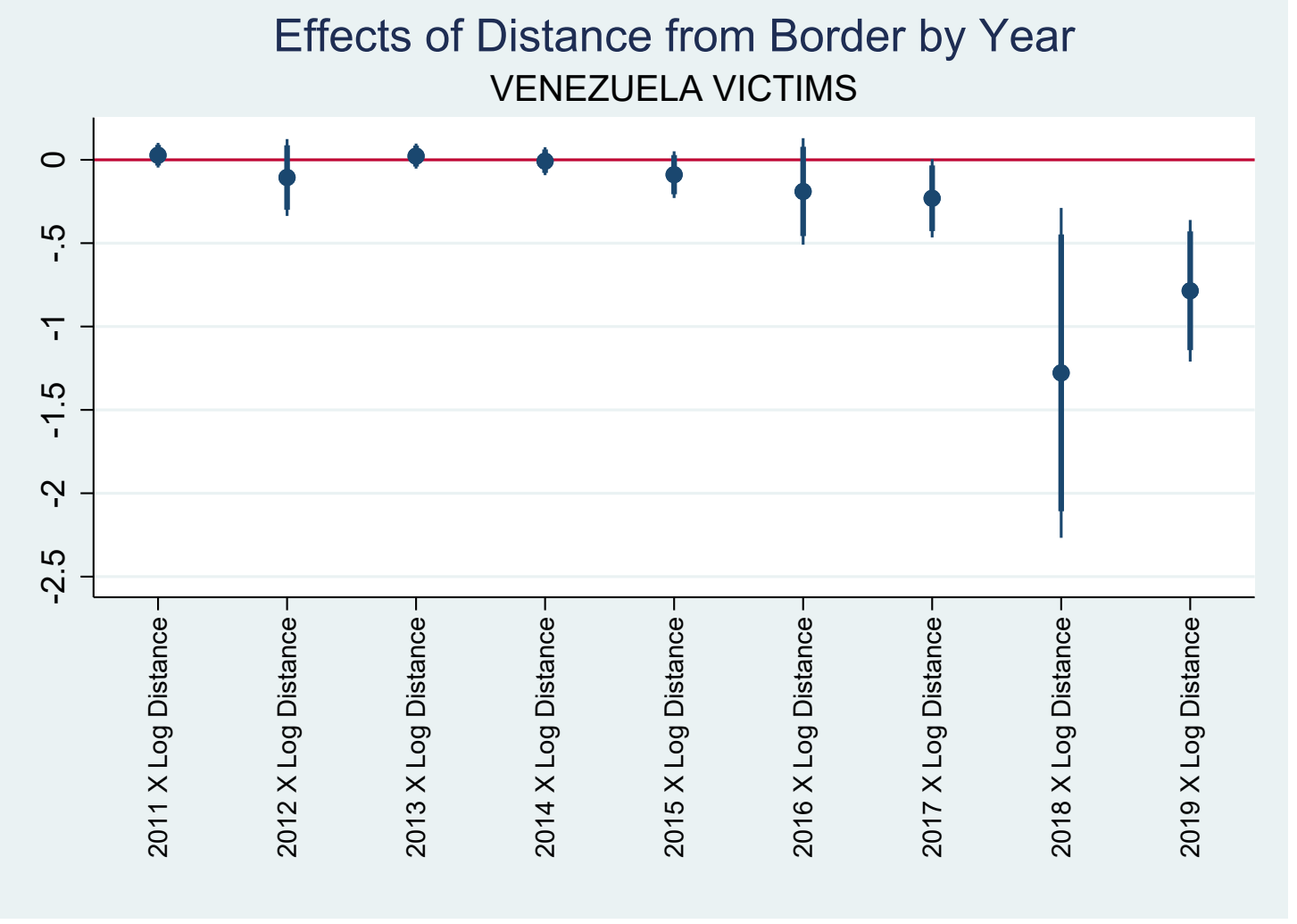

Figure 8

Effects of Distance from Border by Year OTHER VICTIMS

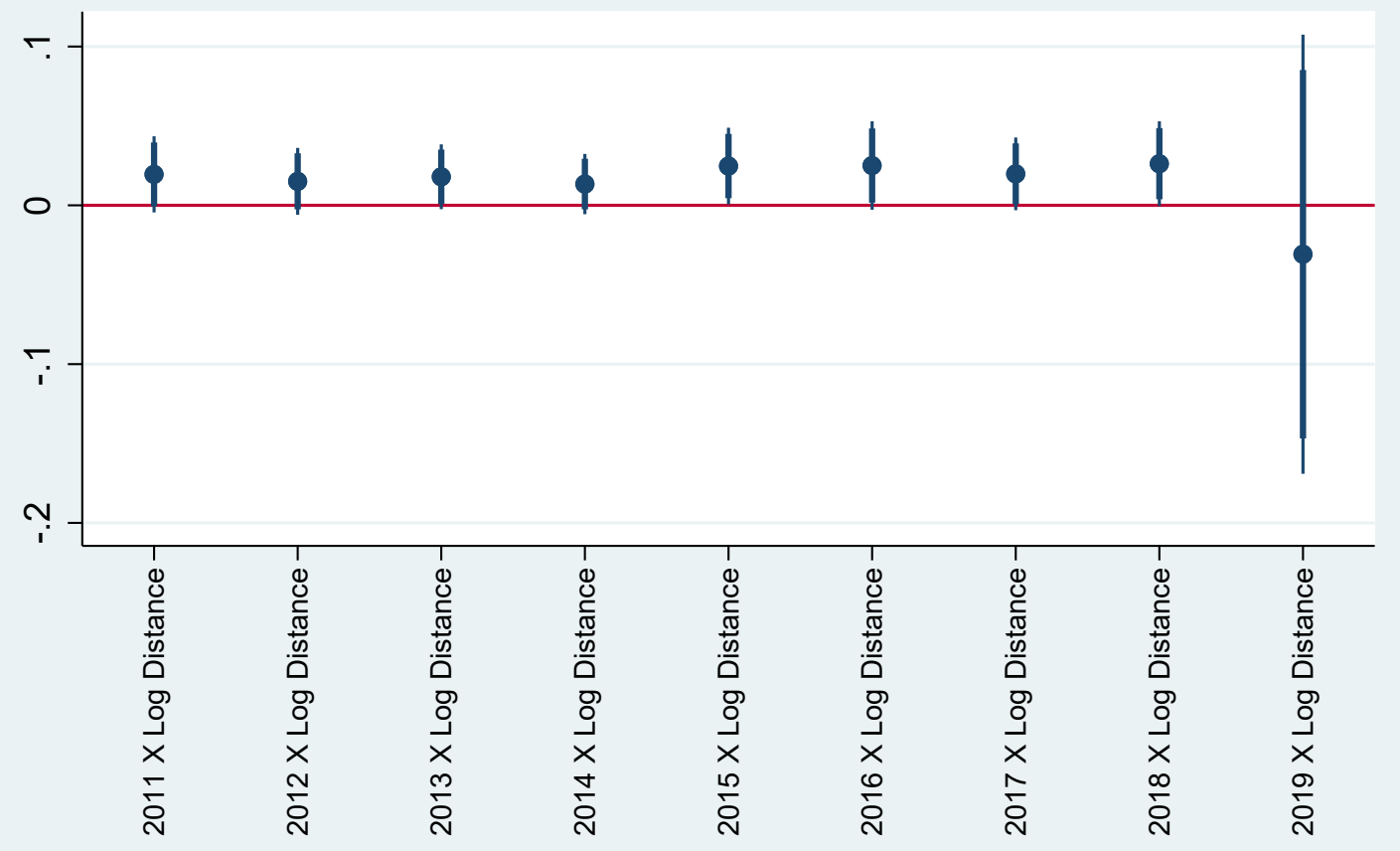

Figure 9 
Effects of Distance from Border by Year MISSING VICTIMS

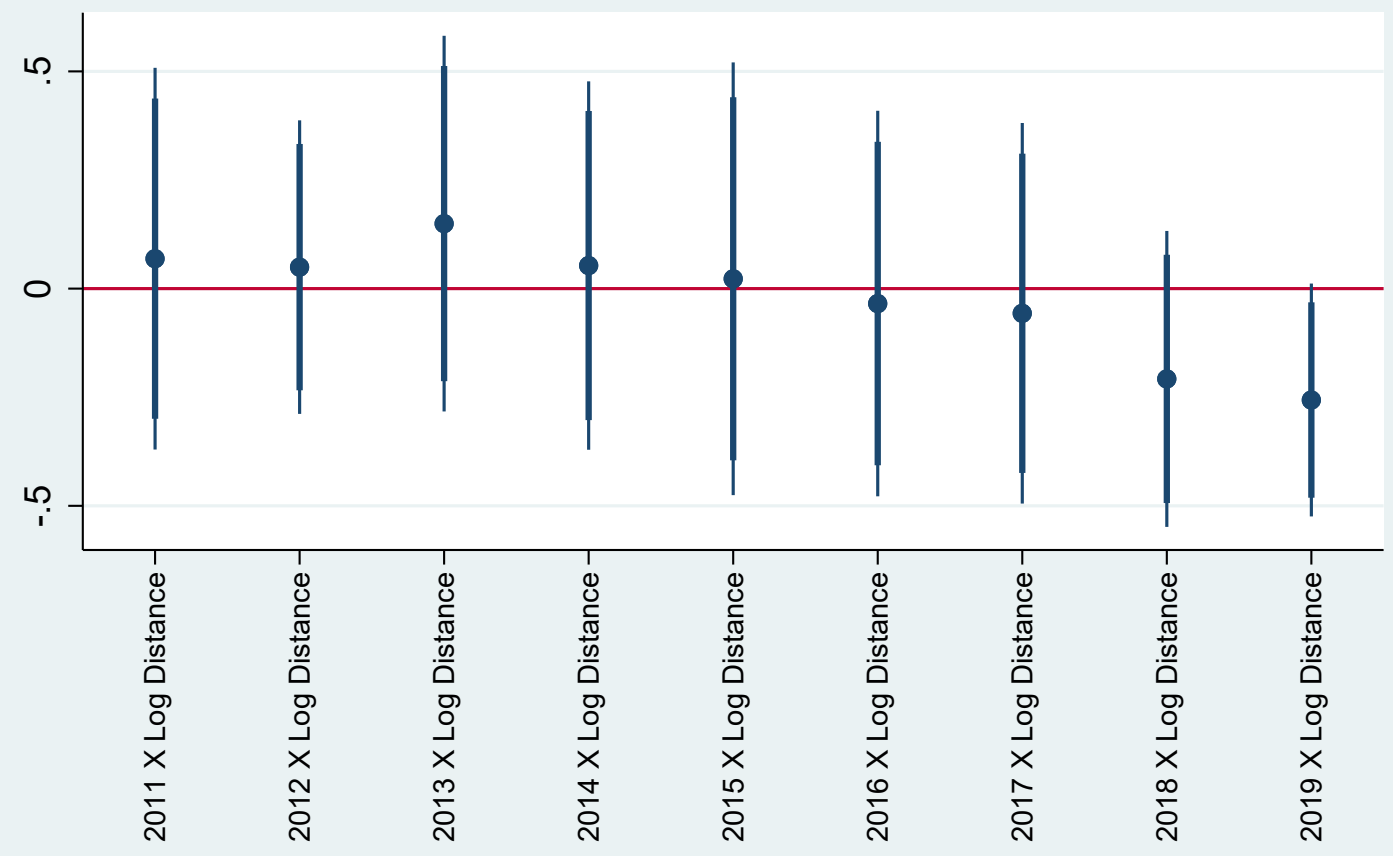

Figure 10

\section{Border Opening Effects by 100 Mile Distance Bins} TOTAL

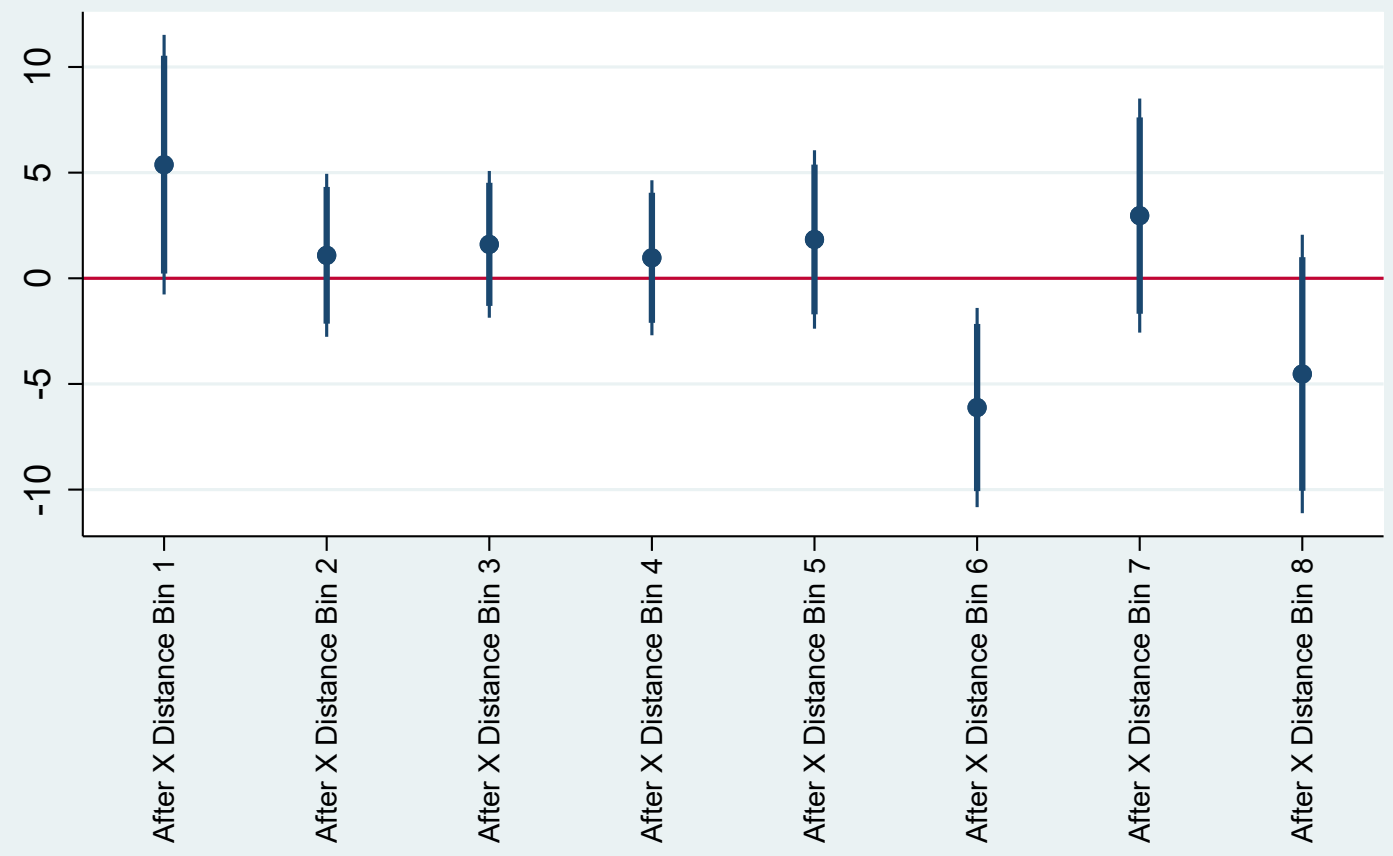

Figure 11 


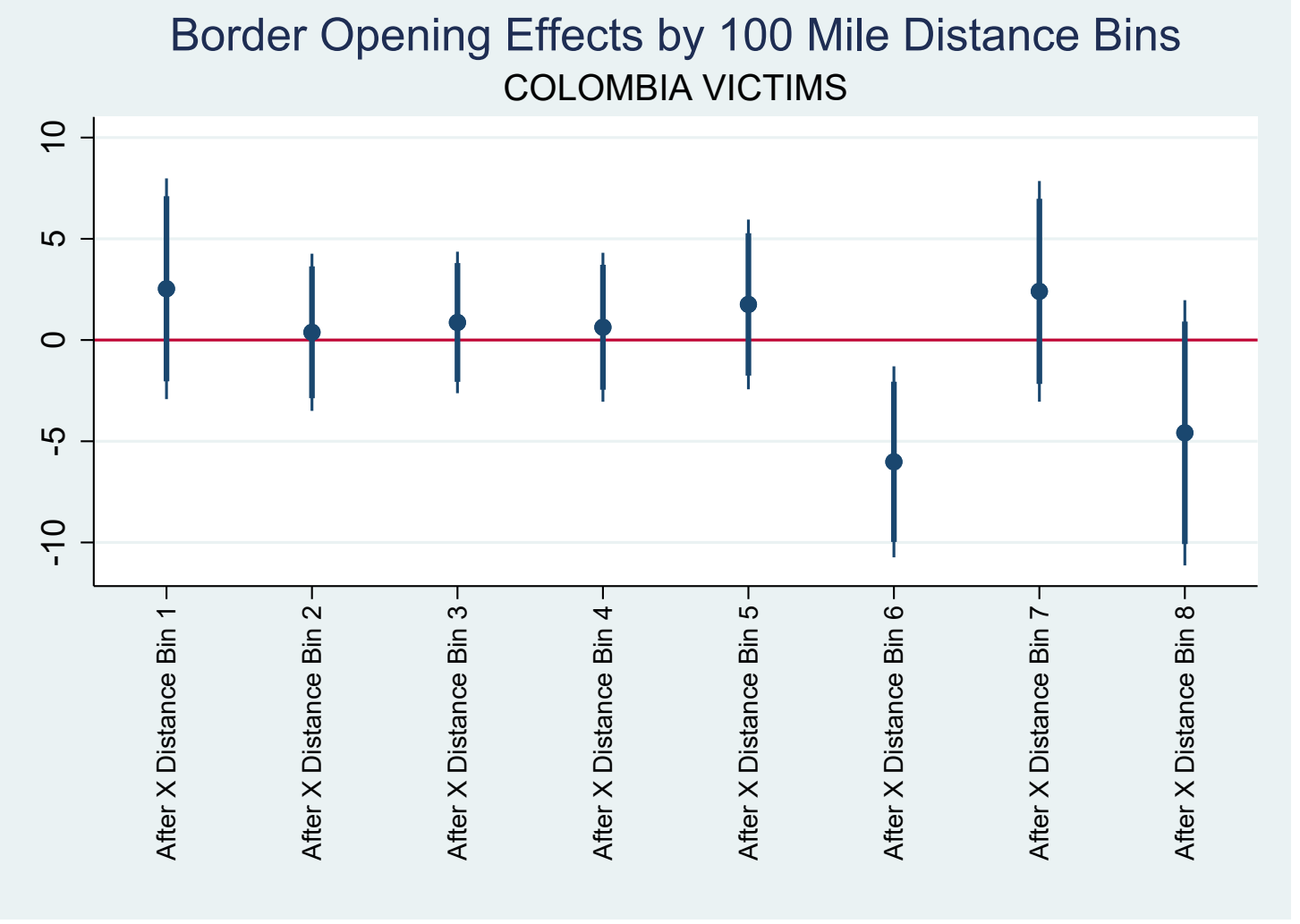

Figure 12

Border Opening Effects by 100 Mile Distance Bins VENEZUELA VICTIMS

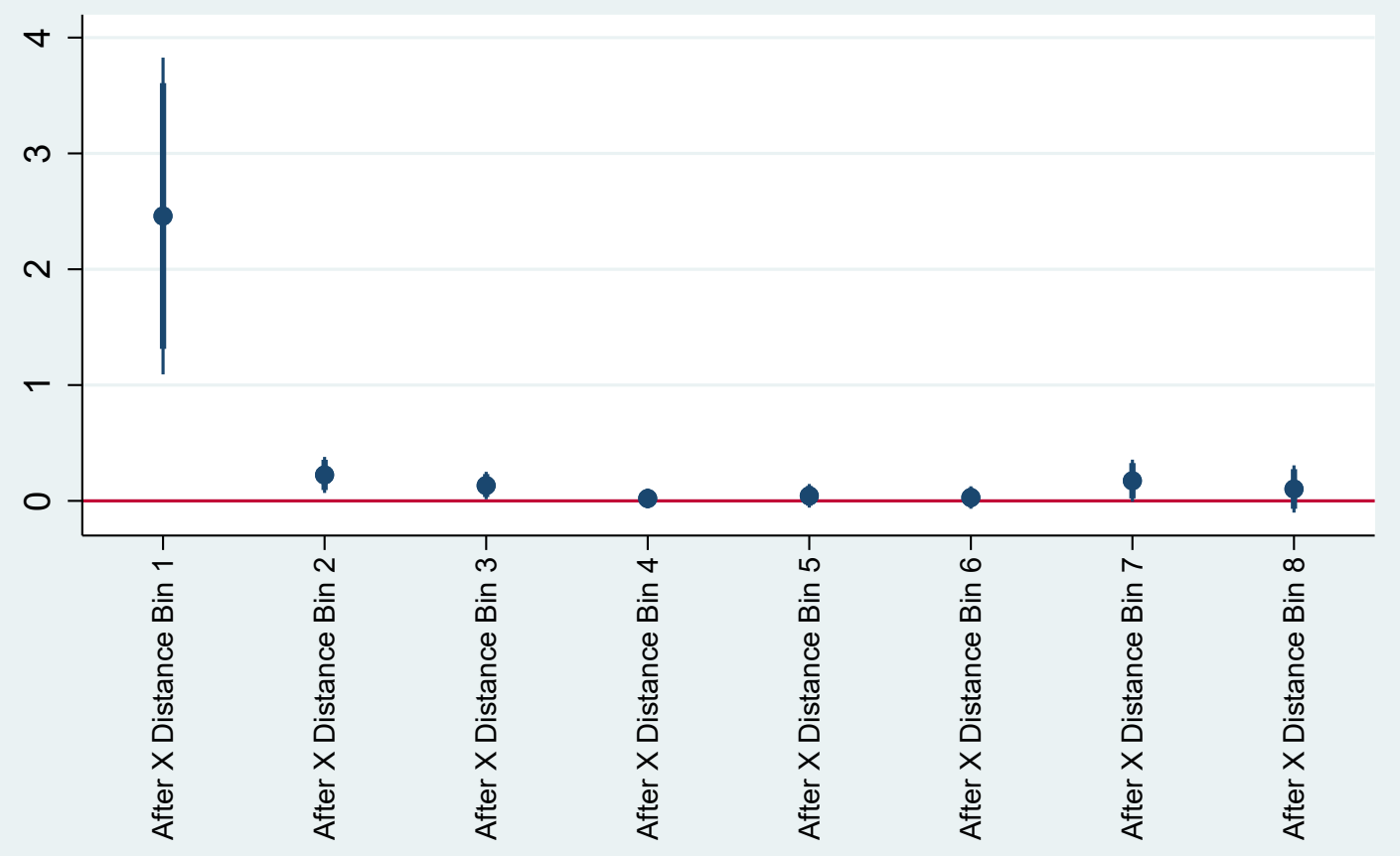

Figure 13 


\section{Border Opening Effects by 100 Mile Distance Bins OTHER VICTIMS}

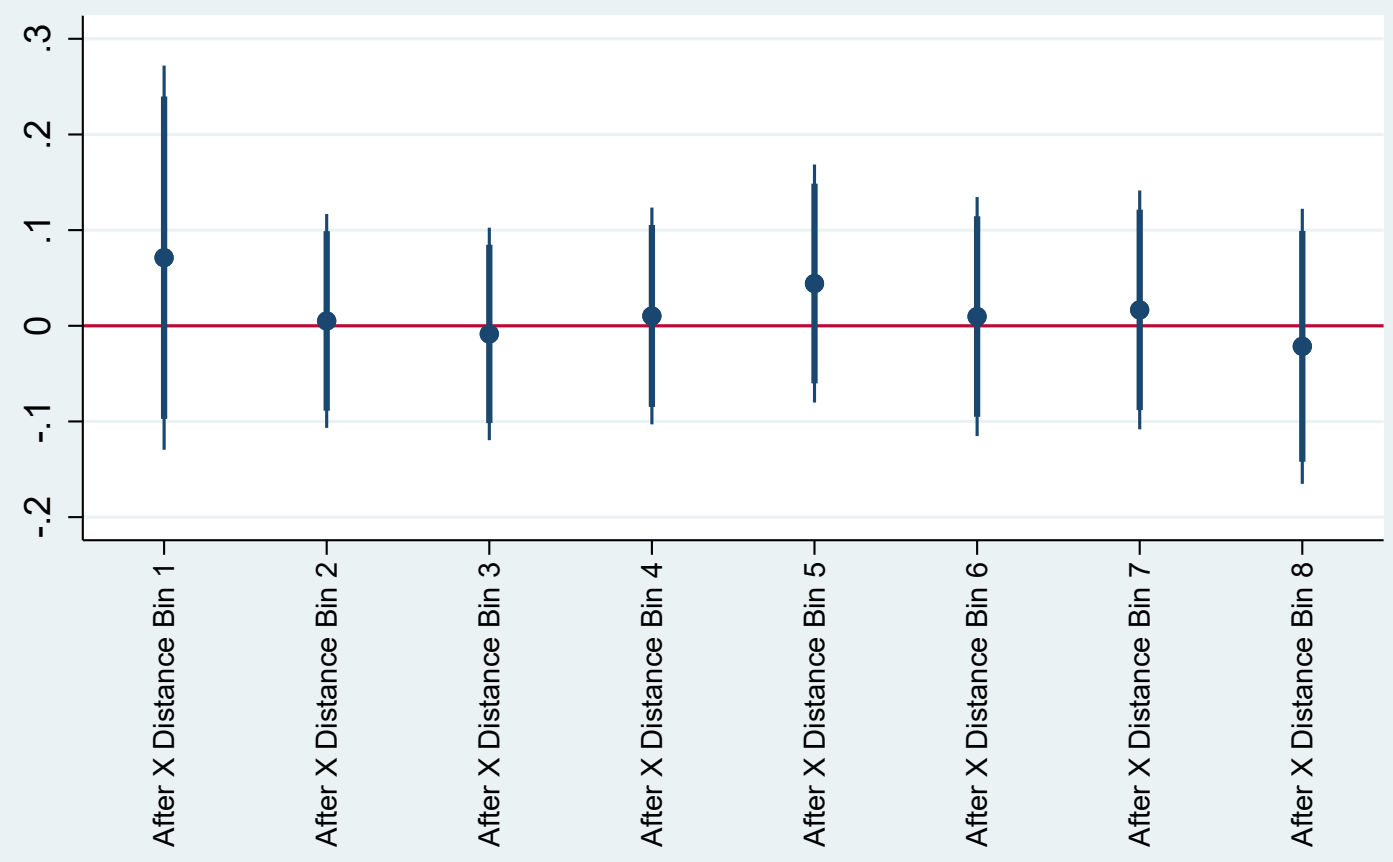

Figure 14

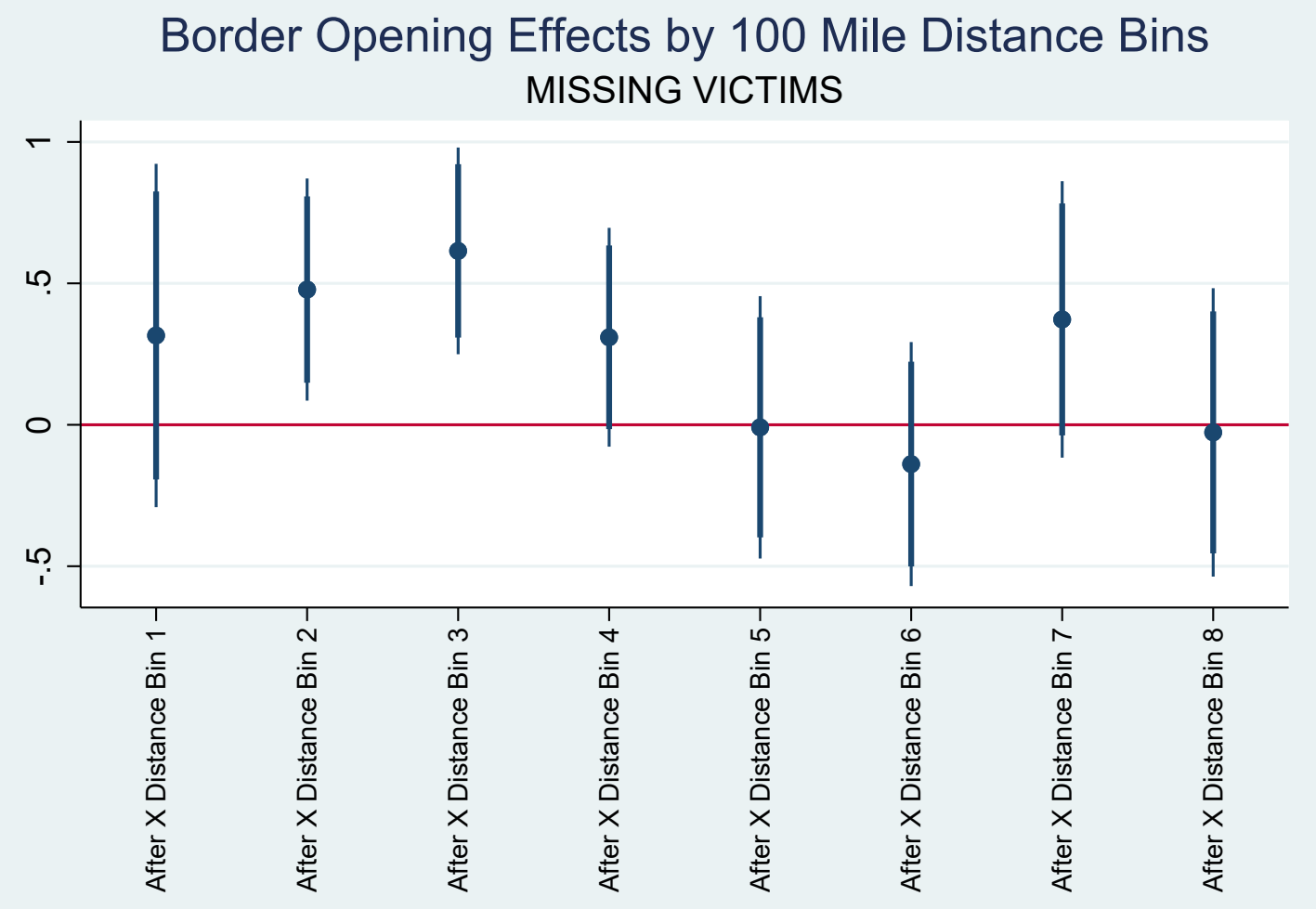

Figure 15 


\begin{tabular}{lccccc}
\hline & $(1)$ & $(2)$ & $(3)$ & $(4)$ & $(5)$ \\
VARIABLES & TOTAL & COLOMBIA & VENEZUELA & OTHER & MISSING \\
\hline After X Log Distance & & & & & \\
& $-1.3865^{* *}$ & -0.5213 & $-0.6387^{* * *}$ & -0.0108 & $-0.2157^{* *}$ \\
& $(0.6279)$ & $(0.5937)$ & $(0.1613)$ & $(0.0216)$ & $(0.0975)$ \\
Observations & & & & & \\
R-squared & 125,880 & 125,880 & 125,880 & 125,880 & 125,880 \\
\hline
\end{tabular}

Dependent variable is homicides per million.

Robust standard errors clustered at municipality level.

Municipality and monthly fixed effects.

*** $p<0.01 * * p<0.05 * p<0.1$

Table 1: Homicides, Border Opening, and Distance

\begin{tabular}{lccccc}
\hline & $(1)$ & $(2)$ & $(3)$ & $(4)$ & $(5)$ \\
VARIABLES & TOTAL & COLOMBIA & VENEZUELA & OTHER & MISSING \\
\hline & & & & & \\
Inflation Rate X Log Distance & $-1.7061^{* *}$ & -0.1968 & $-1.1396^{* * *}$ & 0.0151 & $-0.3848^{* * *}$ \\
& $(0.7368)$ & $(0.6441)$ & $(0.3696)$ & $(0.0104)$ & $(0.1209)$ \\
& & & & & \\
Observations & 125,880 & 125,880 & 125,880 & 125,880 & 125,880 \\
R-squared & 0.1449 & 0.1421 & 0.0467 & 0.0101 & 0.0253 \\
\hline
\end{tabular}

Dependent variable is homicides per million.

Robust standard errors clustered at municipality level.

Municipality and monthly fixed effects.

*** $p<0.01 * * p<0.05 * p<0.1$

Table 2: Homicides, Inflation, and Distance 


\begin{tabular}{lccccc}
\hline \multirow{2}{*}{ VARIABLES } & $(1)$ & $(2)$ & $(3)$ & $(4)$ & $(5)$ \\
& TOTAL & COLOMBIA & VENEZUELA & OTHER & MISSING \\
\hline Log Price Index X Log Distance & $-0.1137^{* *}$ & -0.0174 & $-0.0714^{* * *}$ & -0.0018 & $-0.0232^{* * *}$ \\
& $(0.0576)$ & $(0.0522)$ & $(0.0162)$ & $(0.0034)$ & $(0.0076)$ \\
& & & & & \\
Observations & 125,880 & 125,880 & 125,880 & 125,880 & 125,880 \\
R-squared & 0.1449 & 0.1421 & 0.0465 & 0.0102 & 0.0253 \\
\hline
\end{tabular}

Dependent variable is homicides per million.

Robust standard errors clustered at municipality level.

Municipality and monthly fixed effects.

$* * * p<0.01 * * p<0.05 * p<0.1$

Table 3: Homicides, Distance, and Price Index

\begin{tabular}{lccccc}
\hline & $(1)$ & $(2)$ & $(3)$ & $(4)$ & $(5)$ \\
VARIABLES & TOTAL & COLOMBIA & VENEZUELA & OTHER & MISSING \\
\hline After X Log Distance & & & & & \\
& $-1.5890^{* *}$ & -0.8955 & $-0.4763^{* * *}$ & -0.0145 & $-0.2027^{* *}$ \\
& $(0.6735)$ & $(0.6067)$ & $(0.1349)$ & $(0.0280)$ & $(0.0791)$ \\
Observations & & & & & \\
R-squared & 125,880 & 125,880 & 125,880 & 125,880 & 125,880 \\
\hline
\end{tabular}

Dependent variable is homicides per million.

Robust standard errors clustered at municipality level.

Municipality and monthly fixed effects.

*** $p<0.01 * * p<0.05 * p<0.1$

Table 4: Homicides, Border Opening, and Distance to Maicao/Cucuta 


\begin{tabular}{lccccc}
\hline \multirow{2}{*}{ VARIABLES } & $(1)$ & $(2)$ & $(3)$ & $(4)$ & $(5)$ \\
& TOTAL & COLOMBIA & VENEZUELA & OTHER & MISSING \\
\hline After X Log Travel Time & $-1.1309^{*}$ & -0.2374 & $-0.6666^{* * *}$ & -0.0098 & $-0.2171^{* *}$ \\
& $(0.6004)$ & $(0.5824)$ & $(0.1615)$ & $(0.0219)$ & $(0.1041)$ \\
& & & & & \\
Observations & 125,880 & 125,880 & 125,880 & 125,880 & 125,880 \\
R-squared & 0.1449 & 0.1421 & 0.0437 & 0.0101 & 0.0253 \\
\hline
\end{tabular}

Dependent variable is homicides per million.

Robust standard errors clustered at municipality level.

Municipality and monthly fixed effects.

*** $p<0.01 * * p<0.05 * p<0.1$

Table 5: Homicides, Travel Time, and Price Index

\begin{tabular}{|c|c|c|c|c|}
\hline & (1) & $(2)$ & (3) & (4) \\
\hline VARIABLES & TOTAL & COLOMBIA & VENEZUELA & OTHER \\
\hline \multirow[t]{2}{*}{ After X Log Distance } & -0.1262 & 0.0453 & $-0.1727 * *$ & 0.0012 \\
\hline & $(0.4726)$ & $(0.4192)$ & $(0.0805)$ & $(0.0017)$ \\
\hline Observations & 125,880 & 125,880 & 125,880 & 125,880 \\
\hline R-squared & 0.0426 & 0.0426 & 0.0174 & 0.0092 \\
\hline \multicolumn{5}{|c|}{ Dependent variable is homicides per million. } \\
\hline \multicolumn{5}{|c|}{ Robust standard errors clustered at municipality level. } \\
\hline \multicolumn{5}{|c|}{ Municipality and monthly fixed effects. } \\
\hline \multicolumn{5}{|c|}{$* * * p<0.01 * * p<0.05 * p<0.1$} \\
\hline
\end{tabular}

Table 6: Homicides Arrests, Distance, and Inflation 